\title{
Urocanic Aciduria: A Defect in the Urocanase Activity in the Liver of a Mentally Retarded
}

\author{
Toshio Yoshida, Keiya Tada, Yoshiyuki Honda and \\ Tsuneo Arakawa \\ Department of Pediatrics, Tohoku University School of \\ Medicine, Sendai
}

Yosfida, T., TAda, K., Honda, Y. and Arakawa, Ts. Urocanic Aciduria: A Defect in the Urocanase Activity in the Liver of a Mentally Retarded. Tohoku J. exp. Med., 1971, 104 (4), 305-312 _ A new entity of inborn error of histidine metabolism was described. This was characterized by 1) urocanic aciduria, which was exaggerated after an oral dose of L-histidine, 2) a delayed clearance curve of serum histidine levels after an oral dose of $\mathrm{L}$-histidine, 3) urinary excretion of no detectable amounts of formiminoglutamic acid after an oral load with $\mathrm{L}$-histidine or after an intravenous injection of urocanate, 4) a marked decrease in the urocanase activity of the liver, and 5) mental retardation of probably early onset.—urocanic aciduria ; urocanase; mental retardation; formiminoglutamic acid; histidine metabolism

As inborn errors of metabolism of histidine, histidinemia (Auerbach et al. 1962) and formiminotransferase deficiency (Arakawa et $a l$. 1965) have been reported up to date. The present report deals with a new inborn error of the histidine metabolism, urocanic aciduria, which is characterized by mental retardation, urocanic aciduria and a defective activity of urocanase of the liver (cf. Fig. 1).

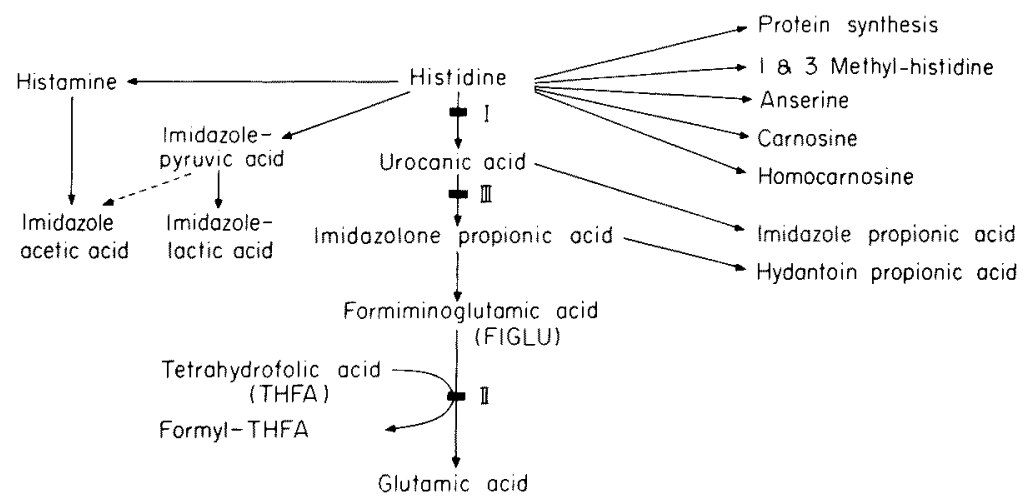

Fig. 1. Metabolic pathways of histidine and biochemical lesions in histidinemia (I), formiminotransferase deficiency syndrome (II) and urocanic aciduria (III).

Received for publication, January, 25, 1971. 


\section{Report of the Case}

T.O., a 16-year-old boy. He was born to healthy and non-consanguineous parents after uneventful pregnancy and delivery, but weighing $2,600 \mathrm{~g}$. His developmental history was not clear, but his physical development seemed to be slightly retarded: sitting up at the age of 11 months, walking alone at the age of 18 months. The patient was suffered from tuberculous meningitis at the age of 19 months, and treated at a local hospital for 10 months and recovered with a sequence of right sided hemiplegia and convulsions. His mother died of pulmonary tuberculosis when the patient was 9 years old.

Since 12 years of age, he has been admitted into an Institution for mentally retarded, Nishitaga, Sendai. On his admission, physical examination revealed a fairly well nourished boy with apathetic countenance. He could not walk alone nor speak any meaningful words. Body weight was $27.4 \mathrm{~kg}$ (normal, $33.0 \mathrm{~kg}$ ), the head circumference being $52 \mathrm{~cm}$ (normal $52.8 \mathrm{~cm}$ ). The lungs and heart were clear on auscultation. The liver and spleen were not palpable. Hemiplegia and contracture were noticed on the right side.

Laboratory findings: Routine urinalysis gave no abnormality. Serum electrolytes, lipids and protein were found to be normal. Peripheral blood picture was that: red cell count was $415 \times 10^{4}$ per $\mathrm{mm}^{3}$, hemoglobin $13.4 \mathrm{~g}$ per $100 \mathrm{ml}$, hematocrit $41 \%$, and white cell count 9,250 per $\mathrm{mm}^{3}$. Liver function tests were negative for CCFT, 8.1 units for ZTT, 1.3 units for TTT, 7 units for GOT, 4 units for GPT, and $22.5 \mathrm{KA}$ units for alkaline phosphatase.

Serum urea-nitrogen was $7.8 \mathrm{mg} / 100 \mathrm{ml}$, fasting blood glucose $82 \mathrm{mg} / 100 \mathrm{ml}$, uric acid $5.2 \mathrm{mg} / 100 \mathrm{ml}$, serum pyruvate $0.93 \mathrm{mg} / 100 \mathrm{ml}$, serum lactate $8.6 \mathrm{mg} / 100$ $\mathrm{ml}$ and serum folic acid (L. casei) $3.8 \mathrm{~m} \gamma / \mathrm{ml}$.

Urinary spot test for metachromasia showed a negative result.

TABLE 1. Serum amino acid levels (umoles/l) of the patient (T.O.)

\begin{tabular}{l|r|r}
\hline Amino acids & Patient (T.O.) & $\begin{array}{r}\text { Normal range } \\
\text { (Tada, 1964) }\end{array}$ \\
\hline Threonine & 49 & $48-134$ \\
Serine & 66 & $216-699$ \\
Glutamine & 320 & $116-181$ \\
Proline & 33 & $62-289$ \\
Glutamic acid & 39 & $164-400$ \\
Glycine & 149 & $168-483$ \\
Alanine & 118 & $80-310$ \\
Valine & 117 & $8-25$ \\
Methionine & 14 & $29-90$ \\
Isoleucine & 19 & $73-164$ \\
Leucine & 42 & $37-97$ \\
Tyrosine & 19 & $28-125$ \\
Phenylalanine & 15 & $17-65$ \\
Ornithine & 27 & $50-148$ \\
Lysine & 146 & $38-70$ \\
Histidine & 56 & Trace- 89 \\
Arginine & 16 & \\
\end{tabular}


TABLE 2. Urinary amino acid levels (umoles/mg of creatinine) of the patient (T.O.)

\begin{tabular}{l|c|c}
\hline Amino acids & Patient (T.O.) & Normal range* \\
\hline Aspartic acid & 0.04 & Trace-0.10 \\
Threonine & 0.23 & $0.17-0.68$ \\
Serine & 0.58 & $0.53-2.94$ \\
Glutamine & 0.83 & $0.10-0.40$ \\
Glutamic acid & 0.17 & $1.39-3.76$ \\
Glycine & 2.87 & $0.51-1.42$ \\
Alanine & 0.51 & Trace \\
a-Aminobutyric acid & 0.05 & Trace-0.28 \\
Valine & 0.25 & Trace \\
Cystine & 0.19 & Trace-0.10 \\
Methionine & 0.06 & $0.07-0.21$ \\
Isoleucine & 0.09 & $0.09-0.37$ \\
Leucine & 0.07 & $0.07-0.61$ \\
Tyrosine & Trace & $0.07-0.51$ \\
Phenylalanine & 0.02 & 0 \\
BAIB & 0.59 & Trace-0. 05 \\
Ornithine & 0.02 & $0.07-0.56$ \\
Lysine & 0.72 & $0.52-2.86$ \\
Histidine & 0.88 & Trace-0.10 \\
Arginine & 0.02 &
\end{tabular}

* Urinary amino acid patterns of normal children, assayed by an automatic amino acid analyzer in our laboratory (Tada 1964).

The urinary excretion of xanthurenic acid after an oral load with tryptophan ( $100 \mathrm{mg}$ per $\mathrm{kg}$ of body weight) was found to be $2.8 \mu$ moles $/ \mathrm{kg}$, being within normal limits.

Free amino acid patterns of the serum and urine were examined with an automatic amino acid analyzer, and were found to be in normal limits (cf. Tables 1 and 2).

Electroencephalography revealed a dysrhythmia. Pneumoencephalography showed an asymmetrical dilatation of cerebral ventricles with the Evans' ratio of 0.50 (cf. Fig. 2 a \& b).

Histological examination of the liver biopsied showed no abnormality.

Chromosome analysis revealed no abnormality in both number and configuration.

Urinary excretion of uric acid was found to be within normal limits.

\section{Special Studies}

Serum histidine levels after an oral load with L-histidine: $100 \mathrm{mg}$ of L-histidine monohydrochloride per $\mathrm{kg}$ of body weight were given orally and serum histidine levels were estimated by an automatic amino acid analyzer. The results showed that the serum histidine levels raised markedly and remained to be higher in the patient than in controls (cf. Fig. 3).

Urinary excretion of imidazole compounds and organic acids after an oral load with L-histidine: Urine specimens were collected for 24 hours after an oral dose 

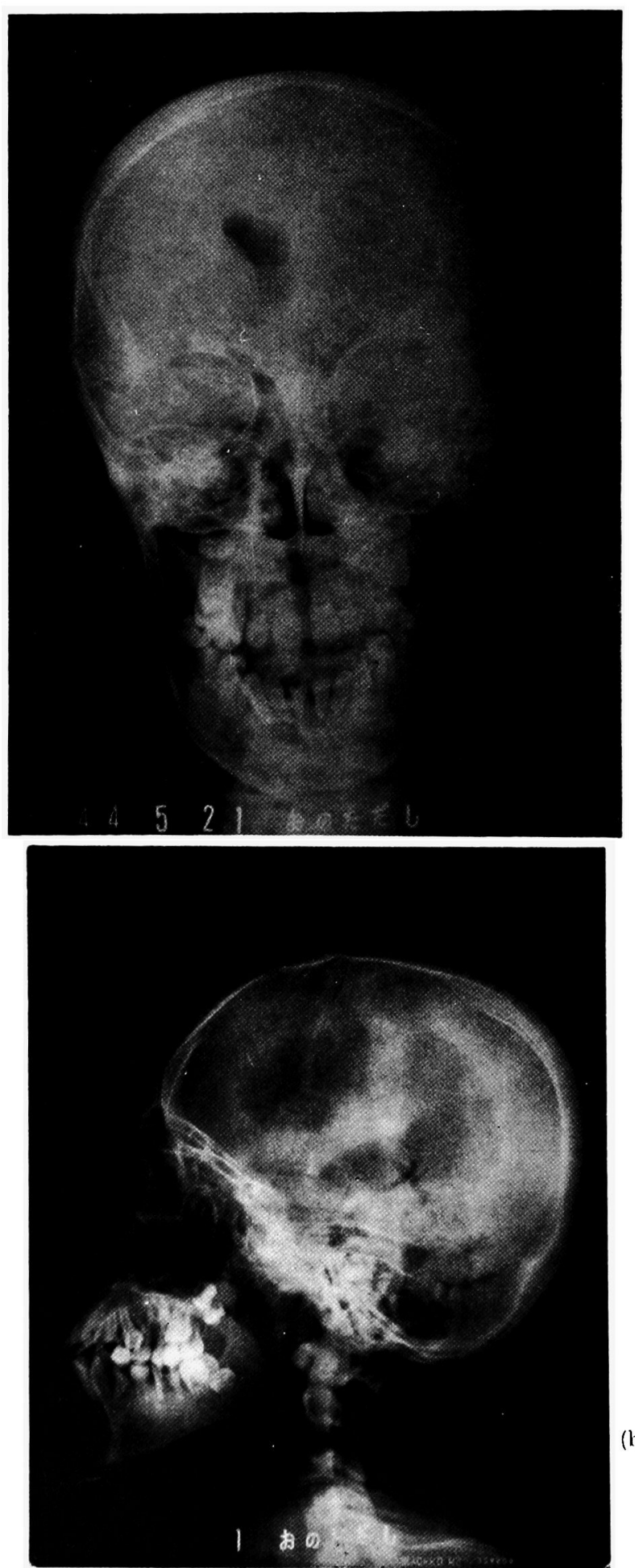

Fig. 2. Pneumoencephalograms of our patient, showing enlargement of the left lateral ventricle and calcified foci. 


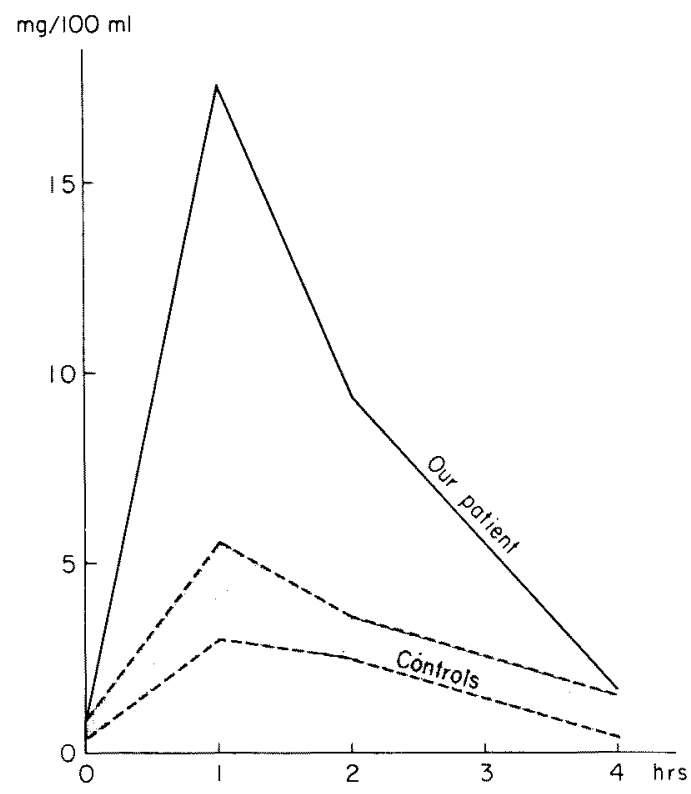

Fig. 3. Histidine tolerance curves in the patient and controls. Histidine monohydrochloride (100 mg per $\mathrm{kg}$ of body weight) was given orally.

of L-histidine monohydrochloride, $300 \mathrm{mg}$ per $\mathrm{kg}$ of body weight, and examined an imidazole compounds (Auerbach et al. 1962, Humbel 1970) and organic acids (Whereat et al. 1968). Large amounts of urocanic acid and considerable amounts of both imidazole pyruvic acid and imidazole propionic acid were detected in the chromatograms of the urine specimens collected after the oral histidine load, which gave a positive reaction for the ferric chloride test.

Neither imidazole pyruvic acid nor imidazole propionic acid was detected by the chromatography in urine specimens from the patient before the oral histidine load and in urine samples from controls with or without the oral histidine dose.

Urocanic acid in the urine specimens after the oral histidine load was estimated semiquantitatively according to Auerbach's method (Auerbach et al. 1962) and it was found that average figure of urinary urocanic acid was 5.49 mmoles per day in the patient, while under 0.1 mmoles per day in controls (cf. Fig. 4).

Histidase activity of the skin: About $10 \mathrm{mg}$ of stratum corneum were obtained from the finger tip skin and used for the assay of histidase by Zannoi and La Du's method (1963). The results showed that there was no difference of the histidase activity between the patient and controls (cf. Table 3).

Urocanase activity of the liver: Liver specimens, $40-50 \mathrm{mg}$ in wet weight, were obtained by a needle biopsy from the patient and two controls without hepatic involvement. The urocanase activity was estimated according to Tabor and Mehler's method (1955) with a slight modification as follows: the reaction system 


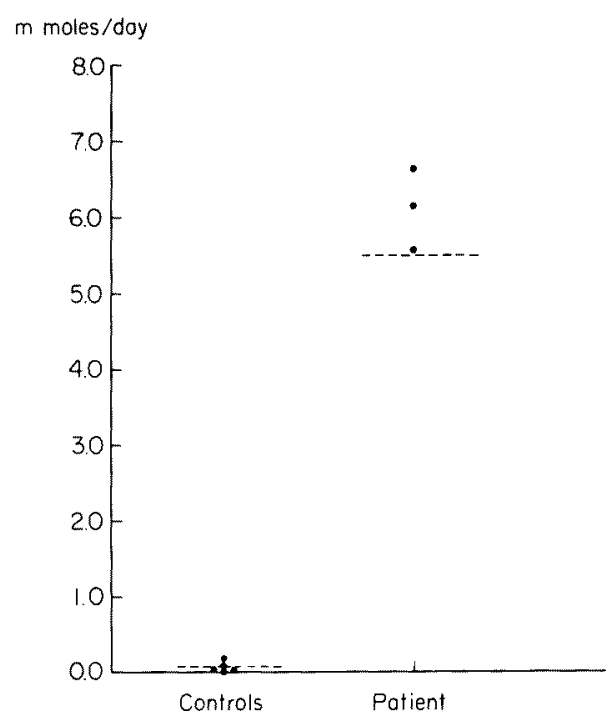

Fig. 4. Urinary excretion of urocanic acid (mmoles per day) after a histidine loading $(0.3 \mathrm{~g}$ of histidine monohydrochloride per $\mathrm{kg}$ of body weight) in the patient and controls.

TABLE 3. The histidase (histidine a-deaminase) activity in stratum corneum

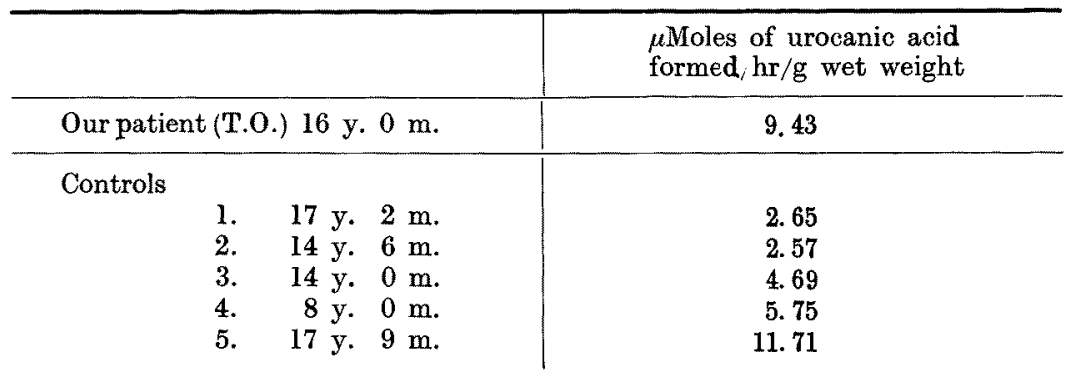

consisted of $1.5 \mathrm{ml}$ of $0.04 \mathrm{M}$ potassium phosphate buffer ( $\mathrm{pH} \mathrm{7.3)}$ containing 20 $\mathrm{mg}$ of liver specimens, and $1 \mathrm{mM}$ of urocanic acid. The incubation was done at $37^{\circ} \mathrm{C}$ for $30 \mathrm{~min}$., and terminated by an addition of $1.5 \mathrm{ml}$ of $5 \%$ perchloric acid. The mixture was well mixed, then centrifuged. The supernatant was used for an estimation of the optical density at $277 \mathrm{~m} \mu$. The precipitate was used for the protein estimation (Lowry et al. 1951).

The blank test was carried out in the same way except that urocanic acid was added after the completion of the incubation.

The urocanase activity was expressed in terms of $\mu$ moles of urocanic acid which were decomposed during the incubation for 30 minutes with the liver specimens.

The results showed that a marked decrease in the urocanase activity of the liver was found in the patient (cf. Table 4). 
TABLE 4. The urocanase activity in the liver from the patient and controls. The urocanase activity was expressed as $\mu$ moles of urocanic acid which were decomposed during the incubation for 30 min with liver specimens

\begin{tabular}{c|c|c}
\hline & $\begin{array}{c}\mu \text { Moles per } \mathrm{g} \text { of } \\
\text { wet weight }\end{array}$ & $\begin{array}{c}\mu \text { Moles per mg } \\
\text { of protein }\end{array}$ \\
\hline Our patient (T.0.) & & \\
$16 \mathrm{y} .0 \mathrm{~m}$. & 0.51 & $0.0059^{\circ}$ \\
\hline Controls & & \\
$1 . \quad 7 \mathrm{y} .2 \mathrm{~m}$. & 2.81 & 0.0427 \\
$2 . \quad 17 \mathrm{y} .7 \mathrm{~m}$. & 4.32 & 0.0658
\end{tabular}

Urinary excretion of formiminoglutamic acid (FIGLU) after an oral dose of histidine monohydrochloride or after an intravenous injection of urocanate: Formiminoglutamic acid (FIGLU) was estimated by Tabor and Wyngarden's method (1959) on urine specimens collected for 8 hours after an oral dose of $\mathbf{L}$-histidine monohydrochloride, $0.33 \mathrm{~g}$ per $\mathrm{kg}$ of body weight. The results revealed that no detectable amounts of FIGLU was found in the patient urine (cf. Table 5).

TABLE 5. Urinary excretion of FLGLU for 8 hours after an oral histidine load $(0.33 \mathrm{~g}$ of L-histidine monohydrochloride per $\mathrm{kg}$ of body weight)

\begin{tabular}{rrr|c}
\hline & & $\mu$ Moles per 8 hours \\
\hline Our patient (T.0.) & & 0 \\
& $16 \mathrm{y}$. & $0 \mathrm{~m}$. & \\
Controls & & & \\
1. & $19 \mathrm{y} \cdot$ & $8 \mathrm{~m}$. & 26.5 \\
2. & $17 \mathrm{y}$. & $11 \mathrm{~m}$. & 40.6 \\
3. & $19 \mathrm{y}$. & $6 \mathrm{~m}$. & 32.9 \\
4. & $10 \mathrm{y}$. & $1 \mathrm{~m}$. & 38.5
\end{tabular}

One gram of urocanic acid dihydrate was dissolved in $33 \mathrm{ml}$ of distilled water and the solution was added with $1 \mathrm{~N} \mathrm{NaOH}$ solution to adjust the $\mathrm{pH}$ to 7.4. The mixture was autoclaved for $15 \mathrm{~min}$., and used for an intravenous injection, in a dose of $33 \mathrm{mg}$ of urocanate per $\mathrm{kg}$ of body weight.

The urine specimens were collected for 8 hours after the intravenous injection of the urocanate solution and assayed for FIGLU. The results showed that no detectable amount of FIGLU was found in the patient urine (cf. Table 6).

TABLE 6. Urinary excretion of FLGLU for 8 hours after an intravenous injection of urocanate (33 $\mathrm{mg}$ per $\mathrm{kg}$ of body weight)

\begin{tabular}{c|c}
\hline & $\mu$ Moles for 8 hours \\
\hline $\begin{array}{c}\text { Our patient (T.0.) } \\
16 \mathrm{y} . \quad 1 \mathrm{~m} .\end{array}$ & 0 \\
\hline Control $10 \mathrm{y} . \quad 5 \mathrm{~m}$. & 10.6
\end{tabular}




\section{Comment}

Our clinical and biochemical investigation upon a 16-year-old boy revealed a peculiar disorder which has not been reported in the literature up to date, which was characterized by 1) urocanic aciduria, which was exaggerated after an oral dose of L-histidine, 2) a delayed clearance curve of serum histidine levels after an oral dose of L-histidine, 3) urinary excretion of no detectable amounts of FIGLU after an oral dose of L-histidine or after an intravenous injection of urocanate, 4) a marked decrease in the urocanase activity of the liver, and 5) mental retardation of probably early onset.

Succinic acid was said to have an inhibitory effect upon urocanase (Hug et al. 1968), but urinary succinate excretion was found to be not increased in our patient.

Mental retardation of our patient seemed to be of early onset, but it was not excluded that the brain lesion due to tuberculous meningitis from which he had suffered at the age of 19 months might participate to some extent in mental retardation of our patient.

\section{References}

1) Arakawa, Ts., Ohara, K., Takahashi, Y., Ogasawara, J., Hayashi, T., Chiba, R., Wada, Y., Tada, K., Mizuno, T., Okamura, T. \& Yoshida, T. Formiminotransferase deficiency syndrome: A new inborn error of folic acid metabolism. Ann. paediat., $1965,205,1-11$.

2) Auerbach, V.H., DiGeorge, A.M., Baldridge, R.C. Tourtellotte, C.D. \& Brigham, M.P. Histidinemia. A deficiency in histidase resulting in the urinary excretion of histidine and of imidazolepyruvic acid. J. Pediat., 1962, 60, 487-497.

3) Hug, D.H., Roth, D. \& Hunter, J. Regulation of histidine catabolism by succinate in pseudomonas putida. J. Bact., 1968, 96, 396-402.

4) Humbel, R. Thin-layer chromatography of urinary imidazoles. Clin. Chem., 1970, 16, 58-59.

5) Lowry, O.H., Resebrough, N.J., Farr, A.L. \& Randall, R.J. Protein measurement with the folin phenol reagent. J. biol. Chem., 1951, 193, 265-275.

6) Tabor, H. \& Mehler, A.H. Histidase and urocanase. Methods in Enzymology., 1955, 2, 228-233.

7) Tabor, H. \& Wyngarden, L. The enzymatic formation of formiminotetrahydrofolic acid, 5,10-metheynyltetrahydrofolic acid and 10-formyltetrahydrofolic acid in the metabolism of formiminoglutamic acid. J. biol. Chem., 1959, 234, 1830-1846.

8) Tada, K. Serum amino acid pattern in normal children, assayed by automatic amino acid analyzer. Rinshoshoniigaku (Jap.), 1964, 12, 129-132.

9) Whereat, A.F., Syndman, D.R. \& Barness, L.A. Thin-layer chromatography of citric acid eycle intermediates, pyruvate and lactate. $J$. Chromatog., 1968, 36, 390393.

10) Zannoi, V.G. \& La Du, B.N. Determination of histidine $a$-deaminase in human stratum corneum and its absence in histidinaemia. Biochem. J., 1963, 88, 160-162. 